\title{
Examining the Fault Behaviour of a Superconducting DC Network
}

\author{
K. M. Davies, P. J. Norman, C. E. Jones, S. J. \\ Galloway \\ Institute for Energy and Environment \\ University of Strathclyde \\ Glasgow, UK \\ karen.davies@strath.ac.uk
}

\author{
M. Husband \\ Strategic Research Centre \\ Rolls-Royce plc \\ Derby, UK
}

\begin{abstract}
A large body of research is currently being conducted into superconducting power system applications, targeting improved efficiency and reductions in system size and weight. In order to attain the required levels of safety and reliability of the superconducting power system, effective protection systems, tailored to the specific fault behaviour of the novel components must also be in place. This paper presents a review of relevant literature concerning the dynamic and transient characteristics of superconducting DC networks and key associated components (such as superconducting cables and machines). This first part of a two stage Failure Modes and Effects Analysis (FMEA) is presented, which provides a conceptual consideration of expected physical failure modes and mechanisms. The effects on the wider network are discussed from which various protection considerations are drawn. A number of key research questions are drawn from this study, which will form the starting point of the second stage of the FMEA. The outputs from the FMEA will shape the protection requirements for a superconducting DC network.
\end{abstract}

Index Terms-Superconducting DC network, Turboelectric Distributed Propulsion, fault studies, FMEA, protection requirements.

\section{INTRODUCTION}

Superconducting power systems technologies and applications are currently the subject of widespread research, where significant improvements in system efficiency, volume and weight in comparison to more conventional systems are expected [1]. Because of such benefits, superconducting technologies are also being considered for future aerospace and marine propulsion systems, with the U.S. Navy's All Electric Ship program [2] and NASA's N3-X concept aircraft [3] being two particularly noteworthy examples. However, whilst there have been several published studies on the characteristics and utilisation of superconducting technologies as part of a conventional grid system [4][5], and also on the development of a fully-superconducting LVDC network [6], there remains a shortage of published work examining failure modes and system-level fault behaviour, which are expected to be fundamentally different to more conventional power systems. As such, there is now a timely requirement to consider this aspect of research, particularly for novel aerospace applications where the electrical propulsion system is considered to be a safety critical element of the aircraft.

Addressing this shortage in knowledge, the authors present a two-stage Failure Modes and Effects Analysis (FMEA) of a superconducting DC network. Building on a review of the relevant literature regarding fully superconducting DC networks and applications, the first stage of this FMEA is a qualitative analysis of various possible failure modes for each of the constituent components considering both the effects local to the failed component as well as the wider network. Through this analysis, aspects of system behaviour which are critical to shaping the protection system requirements and which hence require more than just qualitative analysis are identified. The proposed second stage of the presented FMEA is the further analysis of these behavioural aspects through mathematical and simulation based analysis in order to derive key quantities needed for protection system design.

This paper presents a short review of key research into superconducting DC network technologies and applications. A two stage FMEA is then applied to a characteristic N3-X network. The first qualitative analysis FMEA stage is presented in detail, and is supported by selected elements of the second quantitative analysis stage. Finally, the paper concludes with observations regarding key protection considerations.

\section{OVERVIEW OF SUPERCONDUCTING DC NETWORKS}

The authors of [1] discuss the benefits and operation of a superconducting DC network for grid applications. When operating in the intended state, superconducting materials have zero resistance, which would therefore eliminate power losses from the network. However, a superconducting AC system would suffer from eddy current losses due to the metallic matrix shielding the superconductor, as well as from hysteretic losses in the superconductor itself. Until the materials can be developed such that the AC losses are much lower than current 
This paper is a post-print of the paper published at the IET DPSP conference on the $31^{\text {st }}$ of March 2015 and as such is subject to IET copyright. DOI: $10.1049 / \mathrm{cp} .2014 .0148$

technology allows, superconducting DC transmission looks to be the more viable option. Additionally, as a result of the reduced power losses in the system, a superconducting network would be allowed to operate with a higher current and lower voltage than a conventional network, removing the need for transformer stations [7].

However, superconducting DC networks will suffer from other complications despite the elimination of power losses from DC superconductors. The authors of [1] present a mesh connected DC network to provide redundancy and improve its reliability. This requires power conversion which introduces harmonic currents and associated harmonic losses into the network. They also state that such a network presents issues relating to system protection and control. Due to the lossless transmission lines, each node of the network will reach the same steady state voltage, allowing a voltage droop scheme to be used to control the network. However, the lossless lines also make it difficult to control the flow of current in individual branches of the network and to restore current flow to branches which are reintroduced after being removed from the network. To address this issue the authors of [1] have developed a branch current control scheme that utilises controllable circuit configurations without adding series resistive elements, which would introduce losses to the system [6].

\section{APPLICATIONS OF SUPERCONDUCTING DC NETWORKS}

\section{A. Land based grid applications}

There are a number of ongoing projects utilising superconducting DC technologies, for example the Tres Amigas project in the United States [4] and AmpaCity in Germany [5]. Tres Amigas is planning to connect three sections of the United States' power grid with a superconducting voltage source converter (VSC) DC network to provide more transmission flexibility across the country, and is due to finish in 2016 [4]. In Essen, Germany, AmpaCity plans to replace a $1 \mathrm{~km}$ section of $110 \mathrm{kV}$ conventional cable with a $10 \mathrm{kv}$ superconducting cable [5].

\section{B. All-Electric Ship}

Due to the reduced weight and volume that superconducting technologies offer in comparison to more conventional electrical technologies, their use brings many benefits to the development of the all-electric ship. For example, replacing a conventional motor with an equally rated high temperature superconducting (HTS) motor would result in weight saving of around two thirds and volume savings of around a half, leaving more space for crew's quarters or passenger berths and a larger allowance for fuel and cargo.

\section{Turboelectric Distributed Propulsion}

In an attempt to curb the negative impact that aviation places on the environment, several bodies have challenged the aerospace community to dramatically reduce fuel consumption along with noise and NOx emissions with their upcoming generations of aircraft. For example NASA specify that noise should be reduced by $71 \mathrm{~dB}$, NOx emissions by $80 \%$ and fuel consumption by $60 \%$ with the $\mathrm{N}+3$ generation (i.e. three generations from the current fleet) of aircraft [8]. Turboelectric

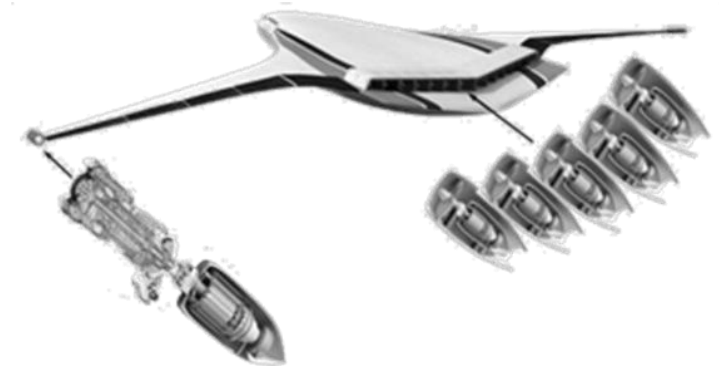

Fig. 1. NASA's N3-X Concept Aircraft

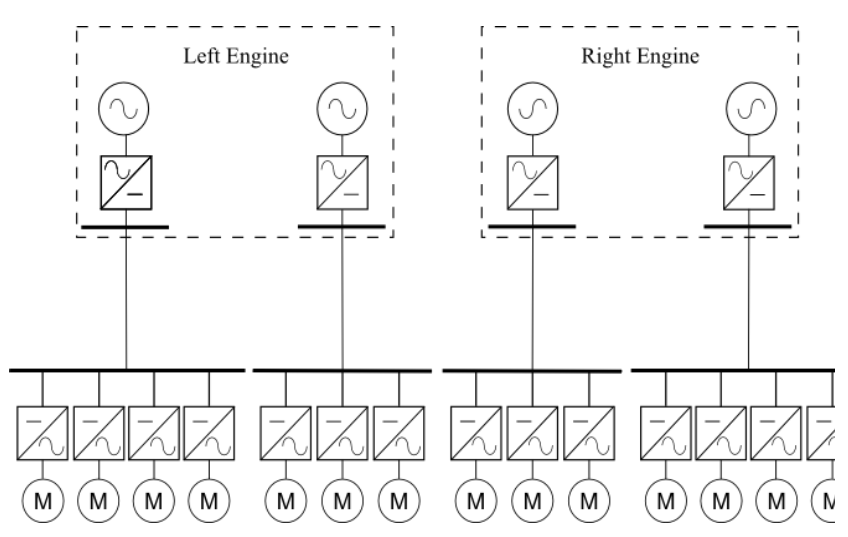

Fig. 2. Candidate architecture of a TeDP aircraft

Distributed Propulsion (TeDP) is a novel design concept which has been identified as key to meeting these targets, and marks a radical change in aircraft propulsion. TeDP has been integrated with a hybrid wing body (HWB) airframe in NASA's N3-X concept aircraft, as shown in Fig. 1. The N3-X comprises two wing-tip mounted superconducting generators which distribute power through a superconducting DC network to fourteen superconducting propulsive motors which are distributed across the aft of the aircraft and produce the majority of the aircraft's thrust [9]. As such the reliability of the electrical network is critical to the safety of the aircraft and, therefore, effective protection solutions are vital to the success of TeDP.

\section{OVERVIEW OF TWO-STAGE FMEA}

Despite the work conducted previously by the authors in [1] and the expanding number of ongoing projects including those covered in the previous section, there is a lack of published literature regarding the fault behaviour of a fully superconducting DC network. The low impedance characteristics of superconducting DC networks could potentially lead to higher fault currents and faster fault propagation than typically experienced in conventional networks. As such, traditional protection approaches may operate too slowly to be of use in such systems.

Furthermore, if the current travelling in a superconducting material exceeds its critical current rating, it will quench and 
return to a resistive state [10]. Similar consequences will arise if the material exceeds its critical temperature or critical magnetic field density, which could also occur with damage to the network's cryogenic cooling system. Under these conditions, the high fault currents commonly seen in more conventional networks may fail to materialize, potentially rendering traditional protection approaches useless.

Given the uncertainty in the development of the fault and the impact on network current and voltage, it is important to develop a comprehensive summary of a superconducting DC system's failure modes to facilitate appropriate protection system design.

In this manner, a two stage FMEA is presented in the following sections. The first stage of the FMEA considers a qualitative analysis of the failure modes of each separate section of a network, the physical effects experienced both locally and network-wide, and the protection considerations which may result. The second stage of the FMEA then further explores aspects of system behaviour which are critical to shaping the protection system requirements through mathematical and simulation based analysis.

\section{QUALITATIVE ANALYSIS OF A N3-X DC SUPERCONDUCTING NETWORK}

In this section, qualitative analysis of the failure modes of an N3-X superconducting DC network is undertaken. A representative breakdown of the network components considered in this analysis is shown in Figure 3. Note that although this particular study is specific to the N3-X aircraft, the outcomes are also applicable to other network types.

\section{A. Superconducting Machines}

\section{1) Operation and performance}

To date the majority of HTS generators and motors are only partially superconducting [11][12]; the rotor normally comprises HTS field windings with an associated cooling system and the stator is manufactured from copper windings operating at room temperature [13]. There are however examples of fully superconducting machines suitable for wind turbine generators which are currently in the design stages [14].

When compared with conventional machines, superconducting machines exhibit lower reactances as the magnetic air gap is larger than that of a conventional machine, due to the extra volume required to house the flux shield and rotor cooling. This leads to larger fault currents in the event of a winding failure. Additionally, superconducting machines have a small field winding resistance when compared with conventional machines. This can lead to slower transient responses than exhibited by conventional machine [15].

2) Failure modes
Two main failure modes of the superconducting machine have been considered in the FMEA; winding faults and cryogenic cooling system faults. For the winding faults, phaseto-ground, phase-to-phase and 3-phase short circuit conditions were considered.

In the event of a short circuit in the machine windings there will initially be a higher transient fault current than typically produced by conventional machines. Indeed, the authors of [15] predict an initial fault current of nine times the partially superconducting generator's rated current for their study. This outcome may not necessarily be true for all machine types however. For fully superconducting machines in particular it may be likely and desirable that the machine windings quench under short circuit conditions, preventing large overcurrents. In these instances, it is important to consider the time constant of the fault in relation to the thermal time constant of the superconducting material affected. The ratio of these will determine the extent to which the fault current develops before the superconducting material quenches, restricting the current flow to negligible levels.

Following a winding short circuit fault, the network voltage will decrease (or collapse completely if quenching occurs) and will typically have a higher than normal ripple content. This will result in a loss of power provision to the downstream buses and loads until corrective action is taken, unless multiple generators with redundant supply paths are present.

In the event of a cryogenic cooling failure there will be a reduced, or depending on the severity of the failure, no current output. The network would experience a loss of voltage and reduction in stability, similar to a short circuit winding fault. However, when compared with low temperature superconducting (LTS) materials, HTS materials have a relatively high heat capacity so are fairly stable against thermal disturbances and it is more likely that the HTS windings would quench due to overcurrent rather than overheating [16].

\section{3) Protection considerations}

Owing to the drop in network voltage introduced by these fault conditions, undervoltage trips may be required depending on the application. For example, aircraft voltage profiles are well defined by standards Mil Std 704F [17] and DO-160 [18] for conventional aircraft. However, such standards do not currently exist for TeDP aircraft.

\section{B. Superconducting Cables}

\section{1) Operation and performance}

There are many different designs of HTS DC cable available; some which have their own dedicated cryocooling "stream" and others which house multiple cables in one collective cryocooling system.

2) Failure modes 
This paper is a post-print of the paper published at the IET DPSP conference on the $31^{\text {st }}$ of March 2015 and as such is subject to IET copyright. DOI: $10.1049 / \mathrm{cp} .2014 .0148$

The failure modes of a superconducting cable will depend somewhat on its construction. For example, a multi-core cable could theoretically experience a phase-to-phase fault with no damage to the cryogenic cooling layer. However, for the same fault to occur with single core cables the cooling system would have to be broken. These two scenarios will produce fundamentally different fault responses.

For the former case, it is expected that significant fault currents will result, combined with a collapse in local and possibly wider network voltage. This behaviour will continue until the fault current is interrupted by protection devices or stemmed by the quenching of a superconducting element in the fault path. As with the machines' considerations, the relative time constants of the fault transient and the quenching component will dictate the extent to which an overcurrent occurs. Further analysis is required in the second stage of the FMEA to obtain estimates of time constants and determine typical system behaviour.

For the latter case, the break in system insulation in the formation of the electrical fault should quench the fault current before any overcurrent forms. However, the relative time constants for both the fault transient and material quenching will once again shape the overall system behaviour.

\section{3) Protection considerations}

The natural failure mode characteristics of the network could give rise to very challenging fault detection requirements. If the network does not quench quickly under short circuit conditions then faults may develop and propagate rapidly, requiring the intervention of fast acting protection to prevent widespread system disruption. The actual required speed of response will require determining through phase two of this FMEA.

If the system quenches quickly under short circuit fault conditions, care must be taken to grade the quench ratings of equipment so that effective protection selectivity is achieved, minimising the total network disruption. Additionally, if circuit breaking equipment is required to remove faulty equipment from the network, the fault location process may be challenging in the absence of sustained overcurrents.

\section{Superconducting Converters}

\section{1) Operation and performance}

It has been shown that power converters operating in cryogenic temperatures have a higher efficiency and reliability, as well as faster switching speeds than those operating at room temperature. Additionally, cryogenic converters have a greater power density than room temperature converters [19].

\section{2) Failure modes}

Two categories of converter failure were considered; switch failure and cryogenic cooling failure. A control failure may also cause fault conditions but is out with the scope of this paper. In terms of switch failures, shoot-through or fail-open faults are both probable. Whilst the single switch failures remain undetected, intermittent short/open circuit conditions will occur with the switching of other healthy switches in the converter. Quenching may occur depending on the magnitude and duration of his intermittent fault current and the associated machine/cable ratings supplying the converter. A faulted converter will result in reduced power quality of supply, or total loss of supply to the downstream elements of the network (unless parallel redundant supply paths are in place).

A cryogenic cooling failure will lead to a quenched converter if its temperature exceeds its critical value.

\section{3) Protection considerations}

Overcurrent or undervoltage protection may be required to protect the converters. This could be implemented through the natural quenching characteristics of the superconducting material itself, circuit breakers or a combination of both. As stated with the cable considerations, care must be taken such that the converter does not quench for downstream fault conditions unless required for a provision of backup protection.

\section{Capacitors and Inductors}

\section{1) Operation and performance}

At cryogenic temperatures ceramic capacitors have been shown to operate as expected up to $200 \mathrm{Vdc}$, and polypropylene and polystyrene capacitors have lower losses and higher withstand voltages. However polyester capacitors undergo a large shift in capacitance and wet electrolytic capacitors freeze and cease to work when cooled to cryogenic temperatures [20].

Conventional inductors experience an increase in magnetic losses and a reduction in copper losses when operated at cryogenic temperatures, resulting in no overall benefit or disadvantage over their room temperature performance [21].

\section{2) Failure modes}

These components are present in multiple locations on the network, for example as part of the AC and DC filters, resulting in many possible failure modes. Each component could potentially fail as either a short or open circuit, or could be subject to a cryogenic cooling system failure.

In the case of capacitors, short circuit faults typically lead to a phase-phase (AC segment) or rail-rail (DC segment) circuit fault, with similar effects to the winding and cable faults discussed before. Open circuit failures would typically lead to a

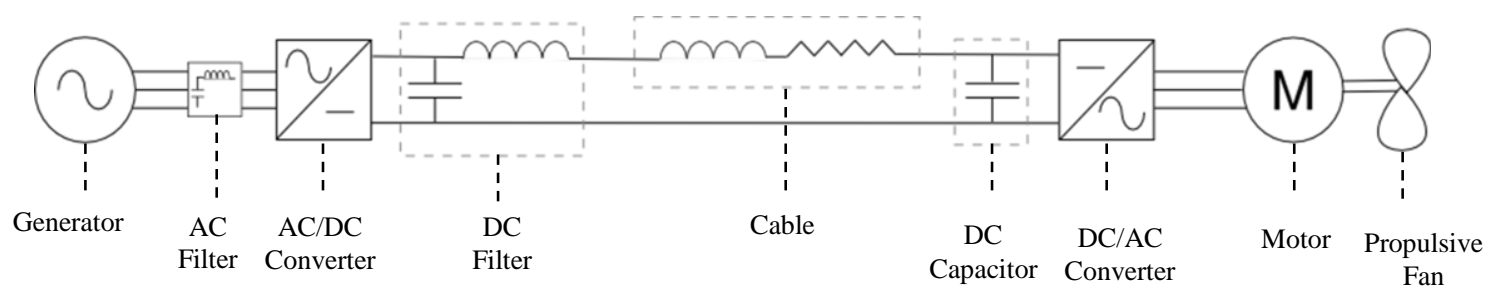

Fig. 3. Superconducting propulsion network 
This paper is a post-print of the paper published at the IET DPSP conference on the $31^{\text {st }}$ of March 2015 and as such is subject to IET copyright. DOI: $10.1049 / \mathrm{cp} .2014 .0148$

reduction in network power quality, which may have secondary effects such as overheating in other network components.

\section{3) Protection considerations}

Perhaps the most noteworthy issue to arise is the detection of capacitor failures. As with earlier discussions, the relative rates at which the fault develops and components quench will determine the extent to which overcurrent conditions develop, shaping requirements for detection of capacitor failures. For inductors, open circuit faults typically lead to a loss of supply to all downstream components whilst short circuit faults will lead to a reduction in power quality.

\section{DisCUSSION AND KEY RESEARCH QUESTIONS}

A number of common critical factors in shaping the fault response of the network to different failures have emerged from phase one of the FMEA. These include; the magnitude of the initial fault current in relation to the critical current density of the HTS material in the fault path, the rate at which the fault current develops, whether the HTS components quench or not, and if they do, the rate at which the system becomes resistive. Further investigation of these factors is required in order to shape the protection system requirements for future superconducting DC networks.

\section{FAULT RESPONSE OF A SUPERCONDUCTING DC NETWORK}

Through modeling and simulation, this section considers the magnitude and time constant of a short circuit fault in a superconducting DC network. The compact DC network is modelled as an RLC circuit (illustrated in Fig. 4) using two sets of cable parameters; one set for a conventional network and the second set for a superconducting network [22]. The parameters used in each case are provided in Table 1.

Figs. 5 and 6 show the fault current and $d i / d t$ profiles for the normal and superconducting networks. It can be seen that a larger and faster fault current peak develops in the superconducting network compared with the conventional network, with the first peak reaching around $12 \mathrm{kA}$ in $200 \mu \mathrm{s}$.

The short time to peak is particularly interesting, as [23] states that "the dynamic resistance of HTS rises rapidly over several tens of microseconds." As such, depending on the timing of the quench initiation, the peak of the fault current may be significantly reduced by the quench action, complicating any fault detection and location necessary. Further simulations employing variable fault path resistances and different superconducting system parameters are required to fully characterise this system behaviour.

\section{CONCLUSION}

Superconducting technologies have many benefits over their conventional counterparts including increased power density, reduced weight and lower DC losses, making them an attractive option for many power applications. In addition to land based grid projects, superconducting DC networks are being considered for propulsion systems as part of NASA's N3-X TeDP aircraft and the U.S. Navy's All Electric Ship program. In the case of the TeDP aircraft, reliable operation of

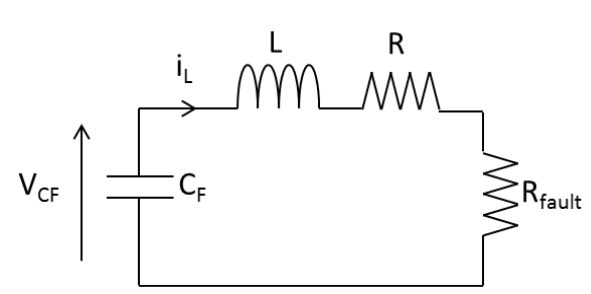

Fig. 4. RLC representation of a superconducting DC network

the electrical network is critical to the safety of the aircraft, hence the protection requirements must be investigated.

Table 1. Simulation parameters for superconducting DC network study

\begin{tabular}{|c|c|c|c|}
\cline { 3 - 4 } \multicolumn{2}{c}{} & \multicolumn{2}{c|}{ Network } \\
\hline Parameter & Unit & Conventional & Superconducting \\
\hline Resistance, $R$ & $\left(\mathrm{~m} \Omega \mathrm{m}^{-1}\right)$ & 0.801 & 0 \\
\hline Inductance, $L$ & $\left(\mu \mathrm{Hm}^{-1}\right)$ & 0.65 & 0.2 \\
\hline $\begin{array}{c}\text { Cable length, } \\
l\end{array}$ & $(\mathrm{~m})$ & 10 & 10 \\
\hline $\begin{array}{c}\text { Filter } \\
\text { capacitance, } \\
C_{F}\end{array}$ & $(\mathrm{mF})$ & 10 & 10 \\
\hline $\begin{array}{c}\text { Initial filter } \\
\text { capacitance } \\
\text { voltage, } \\
V_{C F}(0)\end{array}$ & $(\mathrm{V})$ & 270 & 270 \\
\hline $\begin{array}{c}\text { Fault } \\
\text { resistance, } \\
R_{\text {fault }}\end{array}$ & $(\mathrm{m} \Omega)$ & 10 & 10 \\
\hline
\end{tabular}
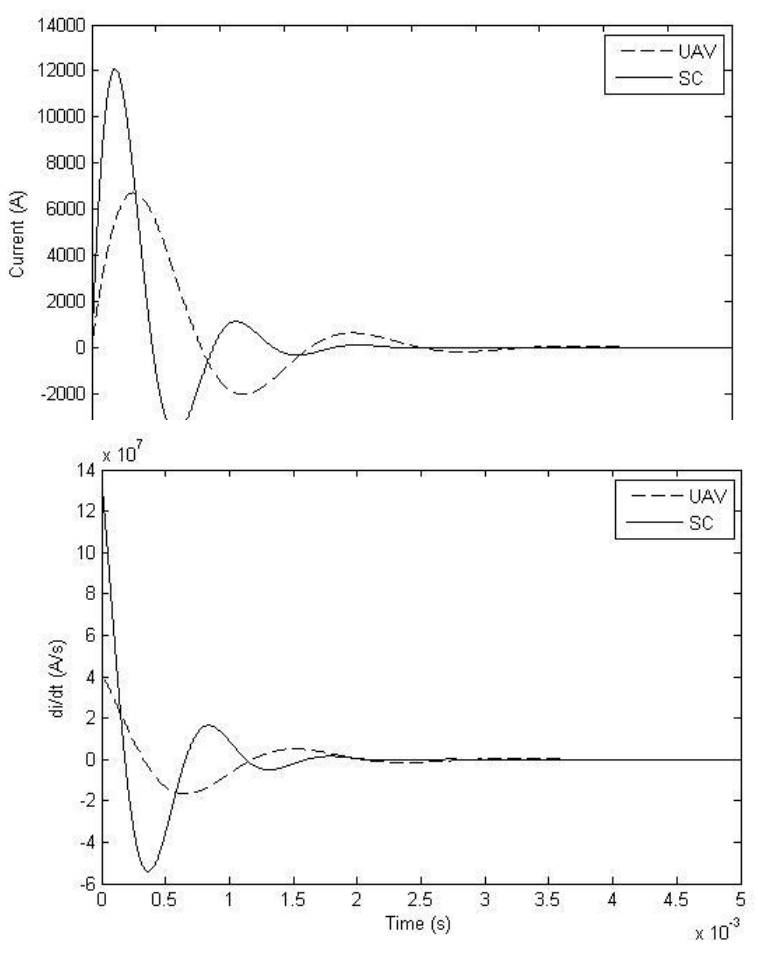

Fig. 6. Comparative $d i / d t$ 
This paper is a post-print of the paper published at the IET DPSP conference on the $31^{\text {st }}$ of March 2015 and as such is subject to IET copyright. DOI: $10.1049 / \mathrm{cp} .2014 .0148$

The authors have presented a two-stage FMEA based approach for determining superconducting protection requirements for a DC network. This is applied in the paper to a TeDP system but is equally relevant to other superconducting DC network applications. From this analysis, a number of key research questions were drawn, informing the more focused second stage of the FMEA, where mathematical analysis and simulations will be utilized to quantitatively determine key attributes of network's fault response, enabling informed protection system design. Initial studies on this second phase are presented where the fault response of a superconducting DC network was simulated in order to determine potential overcurrent peaks and time constants in relation to typical quenching rates of superconducting materials.

A key outcome from this study is the requirement to understand and even carefully design the quench points of various network components. A natural fault current limiting capability may exist in these systems which could complement or even form the basis of the network protection system. Understanding the potential variability in the system fault response as a result of various fault modes and appreciating the desired response from the network and protection system components is crucial to achieving safe, reliable system operation. The analysis framework put forward in this paper provides a useful starting point to achieving this goal.

\section{ACKNOWLEDGMENT}

This work has been carried out as part of the Rolls-Royce UTC programme.

\section{REFERENCES}

[1] B. K. Johnson, R. H. Lasseter, F. L. Alvarado, D. M. Divan, H. Singh, M. C. Chandorkar, and R. Adapa, "High-temperature superconducting DC networks," IEEE Trans. Appl. Supercond., vol. 4, no. 3, pp. 115-120, 1994.

[2] D. Schneider, "The Electric Warship - IEEE Spectrum," IEEE Spectrum, 31-Jul-2013. [Online]. Available: http://spectrum.iee.org/aerospace/military/the-electric-warship. [Accessed: 08-Jan-2014].

[3] J. L. Felder, H. D. Kim, and G. V. Brown, "Turboelectric Distributed Propulsion Engine Cycle Analysis for HybridWing-Body Aircraft," presented at the 47th AIAA Aerospace Sciences Meeting, 2009.

[4] M. A. Reynolds, "Tres Amigas super station - Large scale application of VSC back-to-back technology," in Transmission and Distribution Conference and Exposition (T D), 2012 IEEE PES, 2012, pp. 1-5.

[5] M. Stemmle, F. Merschel, M. Noe, and A. Hoble, "AmpaCity Project-Worldwide First Superconducting Cable and Fault Current Limiter Installation in a German City Center," presented at the 22nd International Conference on Electricity Distribution, 2013.

[6] B. Malek and B. K. Johnson, "Branch Current Control on a Superconducting DC Grid," IEEE Trans. Appl. Supercond., vol. 23, no. 3, pp. 5401005-5401005, 2013.

[7] B. K. Johnson, R. H. Lasseter, and R. Adapta, "Power control applications on a superconducting LVDC mesh," IEEE Trans. Power Deliv., vol. 6, no. 3, pp. 1282-1288, 1991.
[8] NASA Aeronautics, "Environmentally Responsible Aviation Project," presented at the Meeting of Experts, 29-Mar-2012.

[9] M. J. Armstrong, C. A. H. Ross, M. J. Blackwelder, and K. Rajashekara, "Trade Studies for NASA N3-X Turboelectric Distributed Propulsion System Electrical Power Architecture," SAE Int J Aerosp, vol. 5, no. 2, Dec. 2012.

[10] V. S. Mehairjan, M. Popov, A. Geschiere, and W. L. Kling, "Transient Analysis of a $150 \mathrm{kV}$ Fault Current Limiting High Temperature Superconducting Cable," presented at the International Conference on Power Systems Transients, 2011.

[11] C. A. Luongo, P. J. Masson, T. Nam, D. Mavris, H. D. Kim, G. V. Brown, M. Waters, and D. Hall, "Next Generation MoreElectric Aircraft: A Potential Application for HTS Superconductors," IEEE Trans. Appl. Supercond., vol. 19, no. 3, pp. $1055-1068$, Jun. 2009.

[12] M. Frank, P. van Hasselt, P. Kummeth, P. Massek, W. Nick, H. Rothfischer, H. Schmidt, B. Wacker, H.-W. Neumuller, G. Nerowski, J. Frauenhofer, R. Hartig, and W. Rzadki, "HighTemperature Superconducting Rotating Machines for Ship Applications," IEEE Trans. Appl. Supercond., vol. 16, no. 2, pp. 1465-1468, 2006.

[13] S.-J. Jung, G.-H. Kim, H.-J. Sung, K. Kim, M. Park, I.-K. Yu, K. L. Kim, H. Lee, and A.-R. Kim, "Stator Winding Fault Influence on the Field Coil of a 10 MW Superconducting Synchronous Generator," IEEE Trans. Appl. Supercond., vol. 23, no. 3, pp. 5200104-5200104, 2013.

[14] Y. Liang, M. D. Rotaru, and J. K. Sykulski, "Electromagnetic Simulations of a Fully Superconducting 10-MW-Class Wind Turbine Generator," IEEE Trans. Appl. Supercond., vol. 23, no. 6, pp. 46-50, 2013.

[15] S. D. Umans, "Transient performance of a High-TemperatureSuperconducting generator," in Electric Machines and Drives Conference, 2009. IEMDC '09. IEEE Int, 2009, pp. 451-457.

[16] K. Sivasubramaniam, X. Huang, E. T. Laskaris, T. Zhang, J. W. Bray, J. M. Forgarty, and R. A. Nold, "Performance of an HTS Generator Field Coil Under System Fault Conditions," IEEE Trans. Appl. Supercond., vol. 16, no. 4, pp. 1971-1975, 2006.

[17] United States Government, "MIL-STD-704F." United States Government, 30-Dec-2008.

[18] "AC 21-16G - RTCA Document DO-160 versions D, E and F, 'Environmental Conditions and Test Procedures for Airborne Equipment' - Document Information,” 22-Jun-2011. [Online]. Available:http://www.faa.gov/regulations_policies/advisory_cir culars/index.cfm/go/document.information/documentID/101928 0. [Accessed: 08-Jan-2014].

[19] K. Rajashekara and B. Akin, "A review of cryogenic power electronics - status and applications," in Electric Machines Drives Conference (IEMDC), IEEE Int.., 2013, pp. 899-904.

[20] A. I. Gardiner, S. A. Johnson, and E. Schempp, "Operation of power electronic converters at cryogenic temperatures for utility energy conditioning applications," in Energy Conversion Engineering Conference, 1996. IECEC 96., Proceedings of the 31st Intersociety, 1996, vol. 4, pp. 2209-2214 vol.4.

[21] J. H. Claassen, "Inductor design for cryogenic power electronics," IEEE Trans. Appl. Supercond., vol. 15, no. 2, pp. 2385-2388, 2005.

[22] S. D. A. Fletcher, P. J. Norman, S. J. Galloway, and G. M. Burt, "Determination of protection system requirements for dc unmanned aerial vehicle electrical power networks for enhanced capability and survivability," IET Electr. Syst. Transp., vol. 1, no. 4, pp. 137-147, 2011. 
This paper is a post-print of the paper published at the IET DPSP conference on the $31^{\text {st }}$ of March 2015 and as such is subject to IET copyright. DOI: $10.1049 / \mathrm{cp} .2014 .0148$

[23] M. Qiu, Y. B. Lin, H. Y. Zhao, M. Liu, Y. Zhang, J. Fang, L. Z. Lin, and L. Y. Xiao, "The Concept and Technical Analysis on Cryogenic VSC-HVDC System," in International Conference on Power System Technology, 2006. PowerCon 2006, 2006, pp. $1-7$ 